\title{
An isolated unusual digit metastasis from esophageal carcinoma: a case report
}

\author{
This article was published in the following Dove Press journal: \\ OncoTargets and Therapy \\ 9 May 2017 \\ Number of times this article has been viewed
}

\author{
Yi Chen ${ }^{1,2, *}$ \\ Weiwei Tang ${ }^{3, *}$ \\ Hua Xiao ${ }^{3}$ \\ Jinfei Chen' \\ Huanyu Zhao' \\ Junfeng Shi'
}

'Department of Oncology, Nanjing First Hospital, Nanjing Medical University, ${ }^{2}$ Department of

Oncology, Nanjing Pukou Central Hospital, ${ }^{3}$ Department of General Surgery, Nanjing First Hospital, Nanjing Medical University, Nanjing, People's Republic of China

*These authors contributed equally to this work
Correspondence: Junfeng Shi;

Huanyu Zhao

Department of Oncology, Nanjing First

Hospital, Nanjing Medical University,

Changle Road 68, Nanjing 210006,

People's Republic of China

Tel +86 $2587726234 ;+862506887040$

Email junfengshi 1984@gmail.com;

oncodoc@sina.com

\begin{abstract}
Distant soft tissue tumor metastasis isolated in the digit, presenting as a primary esophageal squamous cell carcinoma is considered extremely rare. Herein, we present a rare case of a 44-year-old male patient with squamous cell carcinoma of the esophagus associated with the clinical symptoms of progressive dysphagia and hoarseness in the course of 2 days. During the second course of chemotherapy, the patient sustained a fall with scald to his right ring finger, while the swelling in the right ring finger was soft, cystic and $2.0 \times 1.8 \mathrm{~cm}$ in size. Then, phalangectomy was performed in his right ring finger and pathologic diagnosis was considered metastasis from the esophagus. Unfortunately, the patient succumbed to this disease within 2 months of diagnosis of metastasis. In conclusion, detection of soft tissue metastasis may have prognostic implications, providing more accessible biopsy sites and helping avoid invasive procedures.
\end{abstract}

Keywords: soft tissue metastasis, phalangectomy, prognostic, progressive

\section{Introduction}

Esophageal cancer (EC) is the sixth most common cause of cancer death worldwide and has become a major health concern, especially in Asia. ${ }^{1}$ In China, esophageal squamous cell carcinoma (ESCC) is the predominant histologic subtype and accounts for nearly $90 \%$ of all types of ECs.

The liver, lung and the bones are the most common sites of metastases in EC, yet metastases to skin and subcutaneous soft tissue (ST) are very rare. ${ }^{2,3}$ For most common malignancies, metastasis to skin and subcutaneous ST often occurs in the breast, lung, kidney, colon, head and neck melanomas. Only 3 cases out of 4,020 cancer patients were confirmed with skin and subcutaneous metastases originating from squamous cell carcinoma of the esophagus in a large retrospective study from Pennsylvania State University College of Medicine. ${ }^{4}$

Distant metastatic malignancies to the digit are extremely rare, accounting for $\sim 0.1 \%$ of all metastatic osseous involvement. ${ }^{5}$ Previous work on this subject resulted in only a few reports, which play a guiding role in properly diagnosing metastases to the hand when the findings described are encountered by phalangectomy surgeons. Hsieh et al reported a patient with pathologically confirmed ESCC metastasis of the left thumb, which occurred 3 months after esophagectomy. Initially, the finger lesion on his left thumb was thought to be caused by accidental burns occurring before he had a whole body bone scan taken prior to an esophagectomy. As a result, physicians must be aware of the possibility of metastasis, even if there is no other concomitant metastatic area. ${ }^{6}$ In Houston and Telepak's study, a 56-year-old man had an 8-month history of dysphagia and was diagnosed with a large basaloid squamous cell carcinoma of the 
esophagus. The tumor work-up, including a three-phase bone scan, revealed no evidence of metastases. Seven months later, the patient returned with a fungating necrotic mass emanating from the tip of the left ring finger. The mass was removed and biopsy revealed metastasis of the esophageal carcinoma. ${ }^{7}$ In addition, Dimri et al reported carcinoma of esophagus with unusual metastasis to the gingiva and phalanx as well. ${ }^{8}$

In this report, we describe a patient diagnosed with ST metastasis from lower ESCC, who succumbed to the disease within 2 months.

\section{Case presentation}

A 44-year-old male with a history of high blood pressure was admitted with the clinical symptoms of progressive dysphagia and hoarseness in the course of 2 days.

Esophago-gastro-duodenoscopy revealed irregular uplift lesions of $5 \mathrm{~cm}$ length, from 28 to $33 \mathrm{~cm}$, and then histopathologic work-up of the specimens confirmed the diagnosis of squamous cell carcinoma of the esophagus (Figures 1 and 2). Computed tomography scan showed a circumferential middlethird esophageal growth, which was $\sim 5 \mathrm{~cm}$ long, with significant regional lymphadenopathy but without extraesophageal spread. There were enlarged mediastinum and paracardiac lymph nodes in the computed tomography image, suggesting positivity for malignancy as well (Figure 3). Unfortunately, the patient lost the opportunity to perform esophagectomy. Taking into account the poor prognostic factors such as transmural extension and lymph node positivity, the patient was given two cycles of Doxorubicin plus cisplatin. During the second course of chemotherapy, he discovered that his right ring finger had a protrusion for the first time, which was soft, cystic and $2.0 \times 1.8 \mathrm{~cm}$ in size (Figure 4). Initially, the patient thought that this protrusion was caused by swelling which occurred 1 day prior.

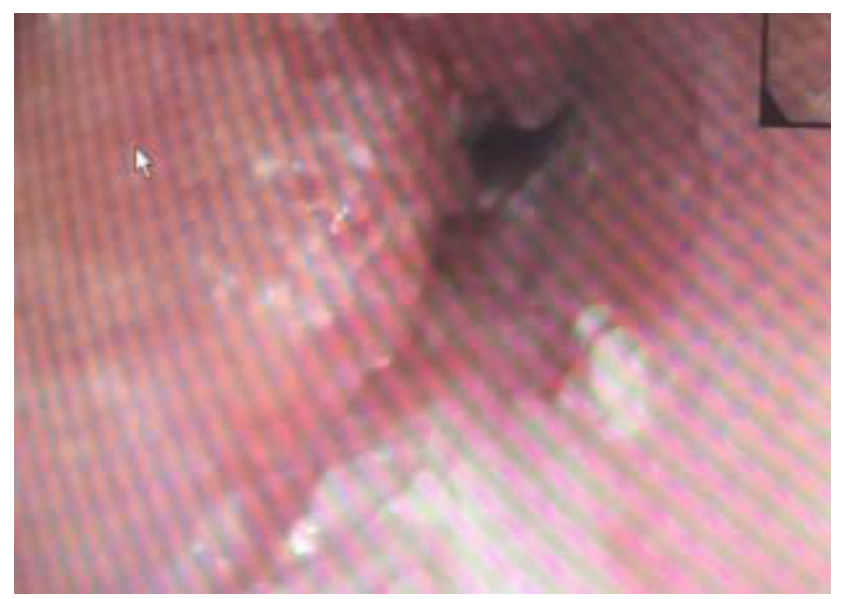

Figure I Esophago-gastro-duodenoscopy imaging.

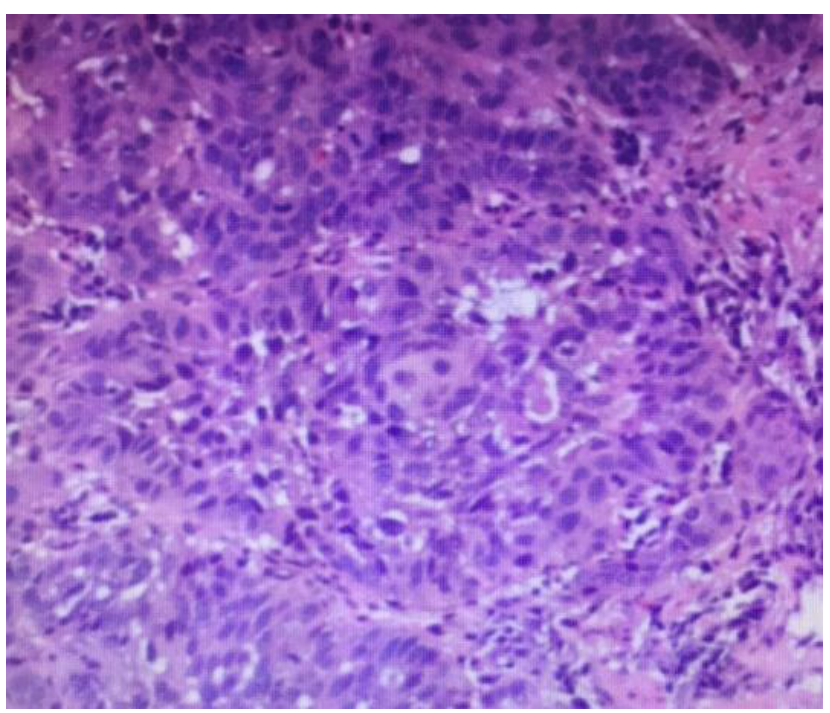

Figure 2 Histopathological imaging of lesions from the esophagus.

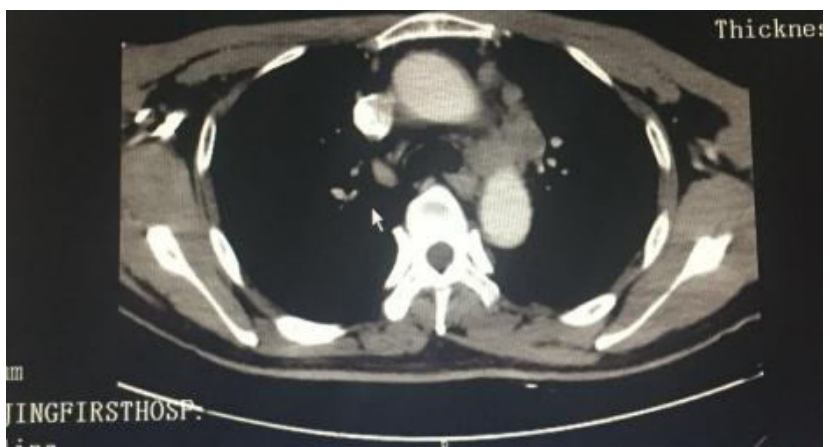

Figure 3 CT imaging of the esophageal and surrounding tissues.

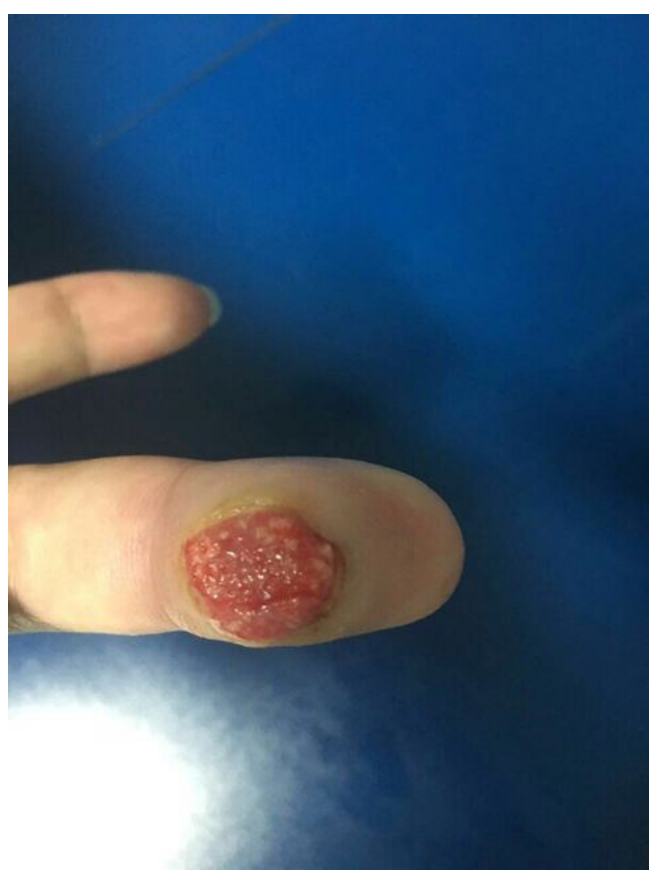

Figure 4 Imaging of the metastases in the right ring finger. 


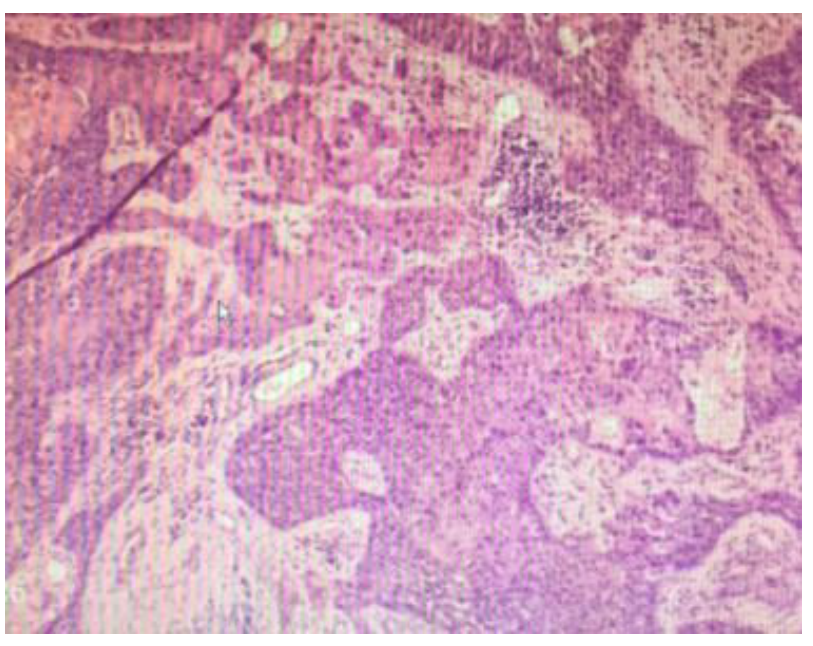

Figure 5 Fine-needle aspiration biopsies imaging from the metastases in the right ring finger.

Unfortunately, fine-needle aspiration biopsies from the site as well as the pathology revealed squamous cell carcinoma (Figures 5 and 6). Radiologic studies revealed no bony metastasis (Figure 7). As a result, this lesion was considered metastatic, as it appeared simultaneously and was reported as squamous cell carcinoma on fine-needle aspiration biopsy. A subsequent metastatic work-up did not reveal any other site of metastases. Then, the patient underwent phalangectomy of his right ring finger. He was planned to undergo palliative chemotherapy and radiotherapy to the metastatic sites, but unfortunately his condition started deteriorating and he succumbed to the disease within 2 months of diagnosis of metastasis.

\section{Discussion}

Distant metastasis to the ST, defined as metastasis to skeletal muscle and subcutaneous tissues, has been rarely reported

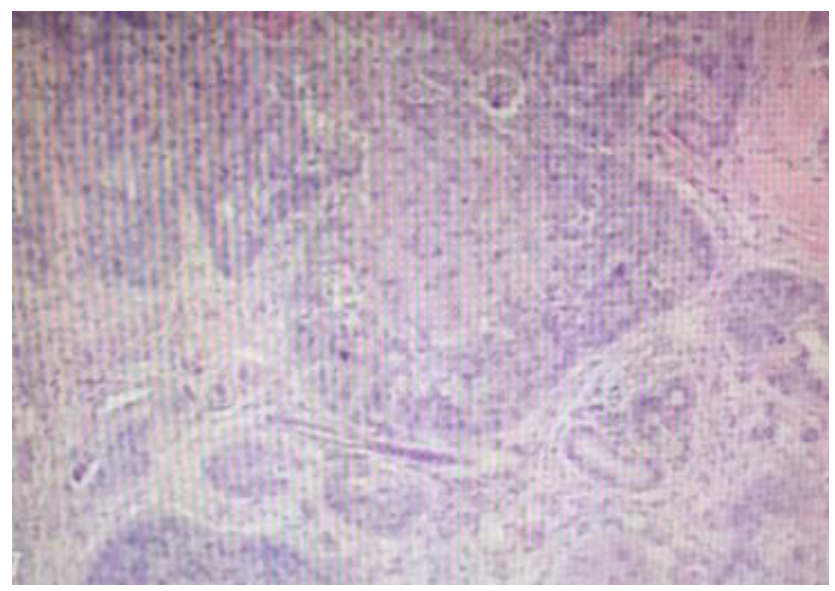

Figure 6 Pathology imaging from the metastases in the right ring finger.

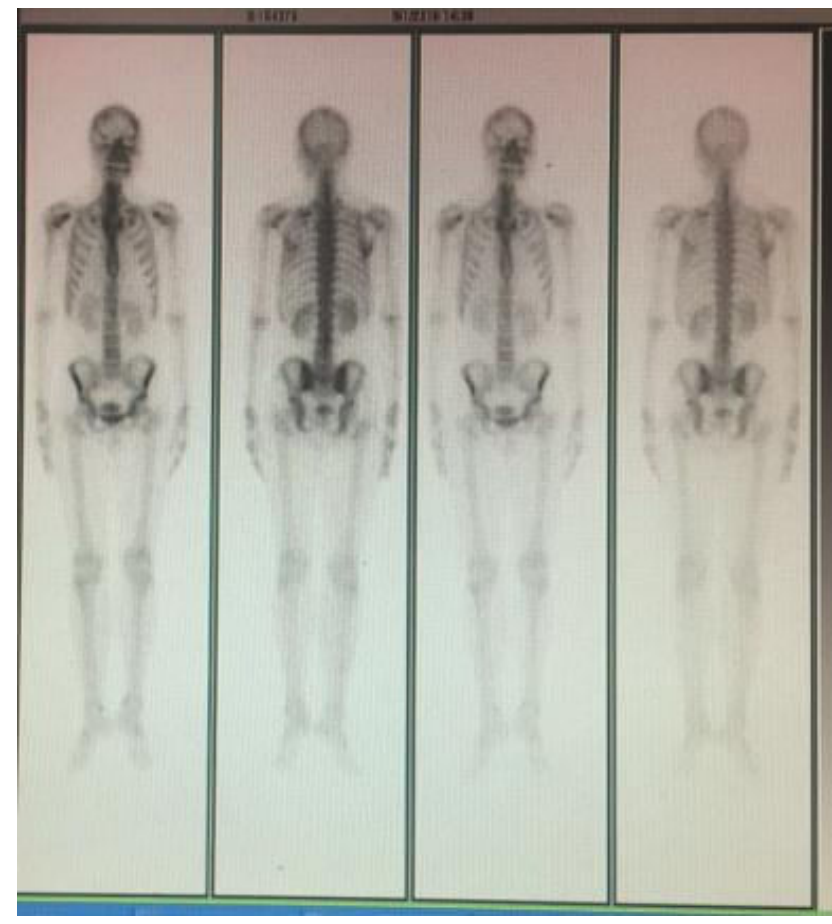

Figure 7 Radiological bone imaging.

in previous studies. The most commonly reported primary carcinomas that result in clinically recognized ST metastasis are those of the lung, kidney and colon. A review of literature revealed the most frequently reported locations for ST metastasis as the back, chest wall and abdomen. ${ }^{9}$ Metastatic tumors to the digit region are uncommon and mostly located in the hand, while only a few are in the ST of digit. Metastases to the digits of hand commonly arise from cancer of the lung, genitourinary tract and breast. ${ }^{7}$ So far, only four cases of metastasis to the phalanx or digital pulp from an esophageal primary have been described. ${ }^{6-8,10}$ Our report has provided a new case for the treatment of ESCC with digit metastases.

In addition, the prognosis in the presence of ST metastasis should be taken into account when weighing the merits of the findings. Distant ST metastasis was associated with poor prognosis, as demonstrated previously. ${ }^{11}$ Our study showed that the patient died of ESCC within 2 months after ST metastasis was diagnosed, which was consistent with Damron and Heiner's study which reported that the median survival ranged from $<4$ months to no more than 18 months after the diagnosis of ST metastasis. ${ }^{12}$ The prognosis of such cases is poor, as the disease has generally disseminated by the time distant ST metastases are diagnosed. Therefore, primary esophageal carcinoma metastasizing simultaneously to distal finger of hand as reported here is an extremely rare presentation and is generally associated with a poor outcome. 


\section{Conclusion}

Detection of ST metastasis may have prognostic implications, providing more accessible biopsy sites and helping avoid invasive procedures.

\section{Acknowledgment}

Written consent was taken from the patient for publishing his clinical details and histopathologic photomicrographs. This work was supported by the Natural Science Fundation of Jiangsu Province (BK20150092, J Shi).

\section{Disclosure}

The authors report no conflicts of interest in this work.

\section{References}

1. Ferlay J, Soerjomataram I, Dikshit R, et al. Cancer incidence and mortality worldwide: sources, methods and major patterns in GLOBOCAN 2012. Int J Cancer. 2015;136(5):E359-E386.

2. Lookingbill DP, Spangler N, Sexton FM. Skin involvement as the presenting sign of internal carcinoma. A retrospective study of 7316 cancer patients. J Am Acad Dermatol. 1990;22(1):19-26.
3. Hedeshian MH, Wang X, Xu B, Fontaine JP, Podbielski FJ. Subcutaneous metastasis from oesophageal cancer. Asian Cardiovasc Thorac Ann. 2006;14(6):520-521.

4. Lookingbill DP, Spangler N, Helm KF. Cutaneous metastases in patients with metastatic carcinoma: a retrospective study of 4020 patients. $J \mathrm{Am}$ Acad Dermatol. 1993;29(2 Pt 1):228-236.

5. Kerin R. Metastatic tumors of the hand. J Bone Joint Surg Am. 1983; 65(9):1331-1335.

6. Hsieh CY, Bai LY, Lo WC, Huang HH, Chiu CF. Esophageal squamous cell carcinoma with a solitary phalangeal metastasis. South Med J. 2008;101(11):1159-1160.

7. Houston JD, Telepak RJ. An isolated digital metastasis of esophageal basaloid squamous cell carcinoma. Clin Nucl Med. 2000;25(7): $557-558$.

8. Dimri K, Rastogi N, Lal P. Carcinoma of esophagus with unusual metastasis to gingiva and phalanx. Indian J Cancer. 2003;40(1):37-38.

9. Schwartz RA. Cutaneous metastatic disease. J Am Acad Dermatol. 1995;33(2 Pt 1):161-182.

10. Silfen R, Amir A, Tobar A, Hauben DJ. The digital pulp as a presenting site of metastatic esophageal carcinoma. Ann Plast Surg. 2001;46(2): 183-184.

11. Balch CM, Buzaid AC, Soong SJ, et al. Final version of the American Joint Committee on Cancer staging system for cutaneous melanoma. J Clin Oncol. 2001;19(16):3635-3648.

12. Damron TA, Heiner J. Distant soft tissue metastasis: a series of 30 new patients and 91 cases from the literature. Ann Surg Oncol. 2000;7(7): 526-534.
OncoTargets and Therapy

\section{Publish your work in this journal}

OncoTargets and Therapy is an international, peer-reviewed, open access journal focusing on the pathological basis of all cancers, potential targets for therapy and treatment protocols employed to improve the management of cancer patients. The journal also focuses on the impact of management programs and new therapeutic agents and protocols on

\section{Dovepress}

patient perspectives such as quality of life, adherence and satisfaction The manuscript management system is completely online and includes a very quick and fair peer-review system, which is all easy to use. Visit http://www.dovepress.com/testimonials.php to read real quotes from published authors. 